\title{
Internalization theory for the digital economy
}

\author{
Elitsa R Banalieva ${ }^{1}$ and \\ Charles Dhanaraj $^{2}$
}

${ }^{1}$ International Business and Strategy Group, D'Amore-McKim School of Business, Northeastern University, Boston, MA 02115-5000, USA; ${ }^{2}$ Fox

School of Business, Temple University,

Philadelphia 19122, USA

Correspondence:

ER Banalieva, International Business and Strategy Group, D'Amore-McKim School of Business, Northeastern University, Boston, MA 02115-5000, USA.

Tel: 617-373-4756;

e-mail: e.banalieva@northeastern.edu

\begin{abstract}
We study the internationalization of digital service multinational enterprises (SMNCs), focusing on how digitalization alters internalization theory's assumptions about the nature of firm-specific assets (FSAs) and the theory's predictions about governance choices in cross-border transactions. We invoke Simon's (Proc Am Philos Soc 106(6):467-482, 1962) near-decomposability concept to explain how digitalization enables two distinct types of FSAs technology and human capital. Applying the ideas of modularity and skill complexity, we further distinguish between core versus peripheral technology FSAs and between generic versus advanced human capital FSAs. Building on the transferability and appropriability of these strategic assets, we theorize on the FSAs' internalization propensity in the digital age. We propose that with rising digitalization, the network plays a dual role - as a governance mode and as a strategic resource. Integrating insights from network economics, particularly increasing returns to scale, we propose that network advantages $\left(\mathrm{O}_{n}\right)$ emerge as a distinct strategic resource that merits separate investigation from the traditional asset-based $\left(\mathrm{O}_{\mathrm{a}}\right)$ and transaction-based $\left(\mathrm{O}_{\mathrm{t}}\right)$ advantages.

Journal of International Business Studies (2019) 50, 1372-1387. https://doi.org/ | 0. 1057/s4 | 267-019-00243-7
\end{abstract}

Keywords:: internalization theory; digitalization; firm-specific assets; governance choices; digital SMNCs; network advantage; human capital FSA; core and peripheral technologies; generic and advanced skills

The online version of this article is available Open Access

\section{INTRODUCTION}

Digitalization has challenged the foundations of the international business (IB) field and forced it to reexamine its priors (Eden, 2016). IB research has long highlighted how information technology is modifying the internationalization process, emphasizing such distinct advantages as reduced transaction costs, user network economies, speed, and scalability (Brouthers, Geisser, \& Rothlauf, 2016; Kotha, Rindova, \& Rothaermel, 2001; Singh \& Kundu, 2002). However, there is a growing awareness that digitalization not only alters the information costs of cross-border transfers of firm-specific advantages (FSAs), but also modifies the very nature of FSAs (Strange \& Zucchella, 2017). Given the proliferation of these
Received: 27 May 2017

Revised: 5 March 2019

Accepted: 2 April 2019

Online publication date: 21 May 2019 
technologies, this paper advances a parsimonious framework to embed digitalization in extant theory. Consistent with the Special Issue's focus on internalization theory (Buckley \& Casson, 1976, 2016), we ask: How does digitalization alter internalization theory's assumptions about the nature of FSAs and predictions about the governance choices in crossborder transactions? We integrate insights from management information sciences (MIS) (Sambamurthy, Bharadwaj, \& Grover, 2003), strategic management (Jacobides, Cennamo, \& Gawer, 2018; Parker \& Van Alstyne, 2005), and network theories (Powell, 1990) to broaden internalization theory for the digital age.

Digitalization is the process of transforming the essence of an organization's products, services, and processes into Internet-compatible data packages that can be created, stored, and transferred in bits and bytes, along with the information associated with them, for marketing, sales, and distribution (Chen, Shaheer, Yi, \& Li, 2018; Sambamurthy et al., 2003). Mobile devices, big data analytics, cloud, social media, 3D printing, additive manufacturing, artificial intelligence $(\mathrm{AI})$, and machine learning are examples of technologies that are driving digitalization. IB studies of Internet or E-Commerce firms have thus far largely focused on service-intensive organizations such as Airbnb, Facebook, Amazon, etc. (Kotha et al., 2001; Singh \& Kundu, 2002). For example, one might contrast the internationalization of Marriott hotels, which took almost 100 years to expand to 122 countries (Marriott, 2019), with that of Airbnb, which took just 8 years to penetrate 190 countries (Solomon, 2016). These service multinational corporations (SMNC) are relatively light on physical assets, use platform technologies, and scale by leveraging their FSAs with local partners' complementary resources (Collinson \& Narula, 2014; Hennart, 2009).

We draw on Simon's (1962) concept of neardecomposability (disaggregating complex systems into a few broad-enough parts) to analyze the differential impacts of digitalization on two FSA types: technology FSAs and human capital FSAs. We also build on Langlois' (2002) and Hennart's (2009) work on modularity, which allows multiple firms to connect seamlessly through interfaces to deliver value to their customers. We link these concepts to digital platforms, which are modular systems, that enable SMNCs to leverage complementary assets from local firms. We further draw on Chi (1994), Kogut and Zander (1993), and Teece (1986) to explore how these FSAs' cross-border transferability and appropriability hazards influence FSA governance choices. Figure 1 outlines our theoretical predictions regarding how digitalization expands the governance mode choice for digital SMNCs.

Our work advances internalization theory in three ways. First, by incorporating digitalization explicitly into internalization theory, we bring the theory's generalizability into the digital era. Our framework connects the organizational design principles of near-decomposability, modularity, skill complexity, and bundling to the phenomenon of digital platforms. A key element of our formulation is the explicit analysis of technology and human capital components of FSAs, which allows one to theorize on the asset-light internationalization enabled by digitalization. Second, we develop governance choice predictions based on knowledge transferability and appropriability and show the emergence of network platforms as the dominant mode in global governance for digital SMNCs. We show that bundling becomes pervasive in such networks, as dominant global firms establish their core technology with walled-in structures to protect their proprietary know-how, while incorporating adaptable design interfaces to link with local firms' capabilities. Third, we propose that the network itself becomes a source of competitive advantage; with rising digitalization, network size and quality emerge as an important resource. In addition to the traditional asset-based $\left(\mathrm{O}_{\mathrm{a}}\right)$ and transaction-based $\left(\mathrm{O}_{\mathrm{t}}\right)$ advantages (Collinson \& Narula, 2014; Dunning, 1988; Lundan, 2009), digitalization introduces the network advantage $\left(\mathbf{O}_{\mathbf{n}}\right)$. We shift the traditional focus exclusively on the sociological arguments of network governance to include the economics of increasing returns from the user networks of the SMNC.

\section{CONCEPTUAL BACKGROUND}

Internalization theory provides a way to explain and predict why and how firms' boundaries stretch across national borders (Buckley \& Casson, 1976). Building on Coase (1937), it suggests that an MNC's international growth is governed by the costs and benefits of internalizing markets in foreign countries. The core tenets of the theory are: firms are profit maximizers in a world of imperfect markets; firms have an incentive to create internal markets to bypass imperfect external markets for intermediate products owned or controlled by the firm; and internalizing the market across national borders 


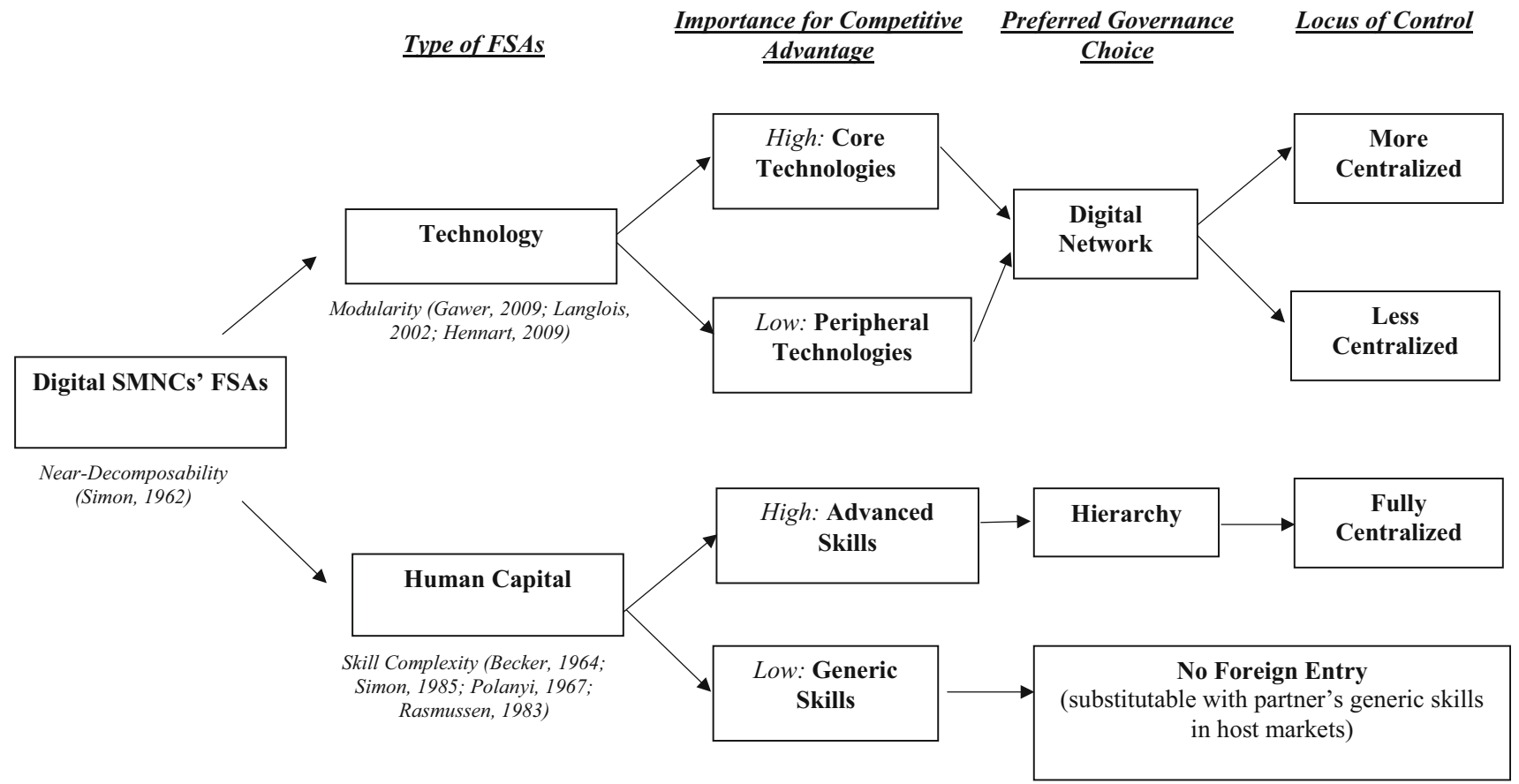

Figure 1 The effect of digitalization on governance choice predictions of internalization theory for digital SMNCs.

creates the MNC (Buckley \& Casson, 1976). Buckley (2016) provides an elegant review of the advancement of the theory over the four decades since it was formulated. We review here three critical developments central to our framework.

Knowledge Transferability across Country Borders Buckley and Casson (1976: 35) assume that "knowledge is a public good within the firm, and its transmission costs are normally low," and thus focus on knowledge appropriability hazards to explain internalization. Kogut and Zander (1992; 1993) advance the notion that complex and tacit knowledge is organizationally embedded, and this knowledge transferability problem is what gives rise to the MNC. Sustainable competitive advantage demands both imperfect imitability (or causal ambiguity) and imperfect mobility (or specificity) (Lippman \& Rumelt, 1982) and thus the literature has moved on to focus on both appropriability hazards and the transferability costs (Kogut \& Zander, 2003). ${ }^{1}$ We build on Chi's (1994) treatise on knowledge assets, highlighting three key attributes of knowledge - tacitness, complexity, and specificity. Following Kogut and Zander (1993), we use the term transferability to refer to the crossborder flow of knowledge, that is at the heart of our study. As internalization is affected by both transferability and appropriability of a firm's FSAs concerns, we explore the impact of digitalization on these two critical constructs. In so doing, we complement other papers in this special issue that also study the cross-border transferability of FSAs through other contingent channels such as, e.g., business groups (Gaur, Pattnaik, Lee, \& Signh, 2019) or the FSAs' appropriability (Wang \& Li, 2019).

\section{Firm-Specific Advantages as Embodiments of Knowledge}

The conceptualization of FSAs is an important building block in the development of internalization theory. Rugman and Verbeke (2003: 127) define FSAs as "knowledge bundles that can take the form of intangible assets, learning capabilities and even privileged relationships with outside actors." FSAs are generally viewed as two types of advantages: asset-based ownership advantages $\left(\mathrm{O}_{\mathrm{a}}\right)$ (e.g., product innovations, marketing capabilities, privileged relationships, etc.) and transaction-based ownership advantages $\left(\mathrm{O}_{\mathrm{t}}\right)$ (e.g., those that emerge from economies of common governance and crossborder coordination) (Dunning, 1988; Lundan, 2009). While early works in IB focused solely on the FSAs of an MNC, Hennart (2009) advocated that one should also include potential local partners' FSAs in the analysis, suggesting that both may be equally critical for an MNC abroad. He suggests 
modularity as a measure of the ease with which a firm's FSAs can be integrated or bundled with the assets of potential local partners. This fusing of foreign and local firms' FSAs in new ways to create innovative capabilities leads to a recombinant advantage that undergirds the competitive advantage of the MNC (Collinson \& Narula, 2014; Pitelis $\&$ Teece, 2018). This also helps to overcome the location-boundedness of some FSAs, if they are highly embedded in the organization or environment or specific to the market (Rugman \& Verbeke, 2004).

\section{Networks as Effective Forms of Knowledge Governance}

The role of networks in internalization theory has evolved over the years. While early works framed governance as a dyadic choice between markets or hierarchies, over the years, hybrid organizational arrangements such as international joint ventures (IJVs) and networks have been actively explored as a third alternative (Buckley, 2016; Hennart, 1993). Drawing on the sociology of networks, the primary argument has been that relational capital in networks mitigates transaction costs through reciprocity and trust (Holm, Eriksson, \& Johanson, 1996, 1999; Powell, 1990). Conversely, digital platforms emphasize the economics of networks, and particularly increasing returns to scale (Bharadwaj, El Sawy, Pavlou, \& Venkatraman, 2013; Parker $\&$ Van Alstyne, 2005). Singh and Kundu (2002), in their analysis of internationalization of ecommerce firms, draw theoretically on Metcalfe's law, with Brouthers et al. (2016) and Chen et al. (2018) providing additional empirical validations. The significance of network externalities inherent in the digital platforms demands consideration of $\mathrm{O}_{\mathrm{n}}$ network advantages as a distinct category from the traditional asset-based (Oa) and transaction-based (Ot) advantages (Collinson \& Narula, 2014; Dunning, 1988; Lundan, 2009). We propose that $\mathrm{O}_{n}$ FSAs, due to digitalization, follow a different logic in terms of location boundedness and isolating mechanisms.

\section{DIGITALIZATION AND INTERNALIZATION THEORY}

Digitalization and Near-Decomposability of FSAs Complex and tacit knowledge embedded in the firm forms the core of an MNC's advantage. Simon's (1962) treatise on the architecture of complexity provides a systematic way to understand how digitalization transforms the knowledge structure behind an FSA. Simon (1962: 474) uses the term "near decomposability" to refer to how complex systems can be simplified into more general subsystems with weak but not negligible interactions among the various sub-systems. Complex systems involve many parts and interactions among them; similarly, nearly decomposable complex systems have both modular and integrated layers, which makes them "quasi-modular" (Gawer, 2009: 350). Simon (1962) suggests that components in nearly-decomposable systems behave almost independently of each other, with greater component interdependencies occurring within rather than between modules (Asmussen, Larsen, \& Pedersen, 2016). Thus, near-decomposability describes the organizing of complex, hierarchical systems into simpler and aggregated parts, without loss of generalization. Building on these insights, we suggest that, for ease of exposition, FSAs can be nearly decomposed into two types: technology (core vs. peripheral) and human capital (advanced vs. generic).

Consider the case of two service firms: McKinsey, a sophisticated management consulting company, and Uber, a digital taxi service company. McKinsey's FSA is strongly dependent on human capital to create value for its customers. The value of the technology component, without the specific human capital, is low for the consulting company. Conversely, Uber's FSA is strongly dependent on technology to create its digital platform. Thus, the decomposability of the FSA into technology and human capital components depends on the knowledge attributes. Highly tacit knowledge embedded in human capital makes it difficult to decompose. While it is difficult to trade such knowledge in markets, it is mobile within a firm. An advantage that is embedded in human capital is sustained by selective hiring, training, socializing, and supporting within a firm. On the other hand, an advantage that is technology-intensive can be sustained by ongoing innovation. Technology FSAs can also be modularized, such that the creation of the technology itself can be centralized, protected, and deployed through bundling with complementary assets of local partners. These arguments lead to our first proposition:

Proposition 1: Digitalization enables the near-decomposability of a firm's FSAs into technology and human capital components. 
We recognize that FSAs do not fall into the category of either pure technology or pure human capital but integrate both. A distinct advantage of digital technologies is the ability to accumulate technology assets into a digital platform that can work in concert with human capital assets. Thus, for ease of exposition, we study the effect of digitalization on each FSA component separately.

\section{The Effect of Digitalization on Technology FSAs}

Technology FSAs comprise a firm's portfolio of information technology (IT)-based innovation processes, patents, copyrights, and trademarks enabled by new digital technologies. SMNCs require a certain core knowledge that needs to be developed at the corporate level and a certain peripheral knowledge at the point of service delivery. For instance, take the case of Uber. The human capital that goes into driving can be decoupled from Uber's technology asset, allowing Uber to build its core knowledge as a corporate technology asset and leverage it with the local driver-partner who contributes the driving and the physical asset (the car). We propose that digitalization increases the transferability of and appropriability hazards for technology FSAs as follows.

\section{Digitalization and cross-border transferability of technology FSAs}

The rapid internationalization of digital SMNCs is enabled by their ability to modularize technology FSAs in such a way as to easily integrate these FSAs with the knowledge assets of host service providers. Modularity is a set of principles that help reduce complexity in a system by breaking the system into separate pieces, "which can then communicate with one another only through standardized interfaces" (Langlois, 2002: 19). Modular systems are decomposable when the interactions among the systems' various modules are negligible (Gawer, 2009; Langlois, 2002; Simon, 1962). IB research has extended the concept of modularity to include asset-bundling (Hennart, 2009) and recombinant advantages (Collinson \& Narula, 2014), enabling firms to compensate for a weakness in one FSA by accessing another FSA. More recent IB research has also elucidated how modularity is related to the creation of architectural knowledge about how the different components of a system are inter-related and function together (Asmussen et al., 2016).
For modularity to work well in a cross-border context, a flexible design interface that will be adaptable at the service end is needed. Digitalization enables this with the use of application programming interfaces (APIs) used on both core and peripheral technologies (Gawer, 2009). An API is a set of routines, protocols, and tools for building software applications. It specifies how software components should interact. API modularity decomposes the application service into pieces that can be delivered in a sequence (Gopal, Ramesh, \& Whinston, 2002). For example, Netflix transitioned from "100 engineers producing a monolithic DVDrental application to a microservices architecture with many small teams responsible for the end-toend development of hundreds of microservices that work together to stream digital entertainment" (Mauro, 2015). In the past, such monolithic service delivery reduced ease of scalability because the entire service had to be upgraded if changes to some parts were needed. Conversely, modern APIs break the service into smaller discrete tasks that can be easily integrated with other digital applications, increasing the speed of international deployment (Gawer, 2009). For example, Airbnb uses its digital platform for information and financial management, recruitment, and regulation of service providers, while the foreign independent service providers interact with the local customers through the platform.

APIs enable modularity not only of intangible assets (e.g., lawyer expertise hired through Legalzoom.com) but also of physical assets (e.g., cars in the case of Uber and Lyft, lodging in the case of Airbnb, vacation home rentals in the case of VRBO, etc.). This increases the global scalability and the relative physical asset-lightness of digital SMNCs. ${ }^{2}$ Uber recently opened its peripheral technology APIs to encourage bundling of its platform with complimentary app services such as hotels, restaurants, etc. (Levine, 2014). As such, APIs are used as building blocks for other platforms, allowing developers to build new capabilities without the need to create the software code from scratch. Chi (1994) points to the two conditions of strategic interdependence that occur during asset bundling: nonexclusion and co-specialization, both of which characterize digital platforms and allow multiple partners to collaborate through the platform. By leveraging specialized resources from local players, the platform creates incremental value for the 
individual partners and for the entire network too. These insights support the following proposition:

Proposition 2a: Digitalization increases the crossborder transferability of a firm's technology FSAs by enhancing its modularity and the firm's ability to bundle it with a local firm's FSA.

\section{Digitalization and appropriability hazards of technology FSAs}

A limitation of technology FSAs is that with geographic transferability barriers down, appropriability risks heighten. Competitive differentiation comes from superior quality of a firm's intangible knowledge resources and the causal ambiguity surrounding them (Reed \& Defillippi, 1990). Sustainable performance emerges from a firm's ability to protect its knowledge against imitability, while promoting transferability of the knowledge across country borders. An interesting observation is that as digitalization makes technology FSAs more easily transferable, it also makes them more easily copied.

Digital SMNCs can raise imitation barriers to sustain their competitive edge by investing in multiple layers of technology FSA protection, which help raise the platform switching costs for their users. The first line of defense is usually investing in raising the complexity of technology, which increases the causal ambiguity and reduces the threat of imitation (Reed \& Defillippi, 1990). Conversely, when standard component technologies are used, causal ambiguity and complexity of the services are compromised as rival platforms can easily perform similar integration. Capabilities embodied in a proprietary core component are observable to rivals when the interface is standardized and, hence, become easily targeted for copy. For example, Didi, Uber's main rival in China, created a similar ride-hailing platform, commoditizing the technology of matching riders with drivers, and forced Uber out of China in 2016. Didi is currently challenging Uber in other foreign markets that are important for Uber: Brazil, Southeast Asia, India, etc. (Pham, 2018).

The second line of defense is the use of proprietary components, without which foreign rivals cannot complete the system assembly. Vertically integrated firms, by virtue of their in-house proprietary technologies, can raise the barriers to imitation (Reed \& Defillippi, 1990). Netflix created such a proprietary algorithm that helped the company understand its global viewers' TV show preferences better (Yu, 2018). Netflix's investments in proprietary big data algorithms enabled the company to amass more subscribers than Hulu, Sling TV, Youtube, etc. combined, and obtain almost $80 \%$ of its 125 million global subscribers from foreign countries (Tutle, 2018). Similarly, Google's search engine uses proprietary algorithms that rank and customize searches based on user preferences. Such proprietary algorithms that solve specific problems and provide actionable insights for companies help sustain competitive advantages in the digital economy (Sondergaard, 2015).

The third line of defense is encryption technologies that make it difficult to reverse-engineer the technology, in essence, "walling off" the core proprietary assets (Roehl \& Truitt, 1987: 92). For example, Amazon is able to keep an edge over its competition owing to triple-walled barriers they invest in, constantly making the system more complex in design, using proprietary components, and building superior encryption that also provides more value to its users on the platform. Amazon's Alexa skills functionality enables users to customize its virtual assistant for different tasks (e.g., book flights, organize trips, call handymen, etc.), enabling Amazon to dominate $70 \%$ of the market of users who use virtual assistants in their homes (Deagon, 2017).

Integrating these layers of technology FSA protection represents a fourth layer of defense. It helps provide more value to users, further strengthening the network effects on the platform (Katz \& Shapiro, 1986) and enhancing the $\mathrm{O}_{n}$ advantage for the digital SMNC. This is because digital networks thrive on cross-sided network effects: the value to users on one side of the platform increases as the quantity and quality of users on the other side of the platform increases too (Katz \& Shapiro, 1986). The more users who actively use the platform globally, the more attractive it becomes, incentivizing vendors, advertisers, and subscribers to join as well. Coupled with the multi-layer technology FSA protection, platforms that reach a certain user size become too dominant to be dethroned, which further enables their competitive advantage in foreign markets (Yu, 2018).

Some international network effects may, however, be more location-bound if the number of global users with similar preferences who join the digital network is only a small share of the total user base worldwide (Suarez, 2005). For instance, millennials on a digital platform may care more about how many other millennials with similar 
interests are subscribed to the platform worldwide with whom they can interact than about other user segments with whom they share fewer similar interests. In such cases, if competitors create alternative platforms that target the specific user group on the dominant digital network, appropriability hazards can arise for the incumbent platform (Suarez \& Kirtley, 2012). For instance, Google and Amazon, despite their established and multi-layer protected technologies, are competing to adapt their AI technologies to understand vernacular in the Indian market where most consumers speak different local dialects. They hope to prevent Indian startups such as Voxta or Liv.ai from preempting the Indian market with their consumer appeal to local language preferences (Mathur, 2018; Modgil, 2017).

In sum, the global success of digital networks is modulated by the integration of multiple layers of technology protection and international network effects among similar users, which helps reduce appropriability hazards globally for the incumbent's digital network. These arguments suggest that:

Proposition 2b: Digitalization increases crossborder appropriability hazards for a firm's technology FSAs, but also enhances the firm's ability to contain imitation by "walling-in" through integrating complex technology, proprietary components, encryption, and network effects.

\section{Digitalization and Human Capital FSAs}

Although human capital has gone largely undiscussed in the discourse surrounding internalization theory, it exists implicitly by the theory's focus on proprietary knowledge. Human capital is the stock of knowledge and skills that individuals develop through education, training, experience, and interactions among their peers (Becker, 1964; Coff \& Kryscynsky, 2011; Mahoney \& Kor, 2015; Nelson \& Winter, 1982). A careful analysis of the IB literature on expatriates suggests, that expatriates (or human capital) have been an important component in the transfer of knowledge and capability to foreign subsidiaries (Harzing, Pudelco, \& Reiche, 2016).

Polanyi (1967) classified knowledge into tacit and explicit. Tacit knowledge or know-how is the knowledge embedded in people, systems, and organizations, and difficult to articulate or codify. Explicit knowledge (or "know-what") is the knowledge which is easily identified, articulated, shared, and employed. Simon (1985) notes that there is a general type of knowledge (e.g., generic skills) and a more industry- or firm-specific type of knowledge (e.g., advanced skills). Nelson and Winter (1982) considered skills and routines central to their evolutionary theory. For the purpose of our theorizing, we use advanced and generic skills as two types of human capital. For example, the skills required from a McKinsey consultant would be the advanced skills and the skills required to drive for Uber will be the generic skills. This builds on the seminal work of Rasmussen (1983) who distinguishes between rule-based skills and knowledgebased skills. Digitalization is a double-edged sword that on the one hand enhances the competitive advantage of human capital built on specialized skills, but on the other hand commoditizes that of generic skills.

Often, advanced skills are needed where individuals are faced with unfamiliar situations, with little guidance from previous encounters. These skills demand intuition and ingenuity (Turing, 1939). Intuition consists of making spontaneous judgments, which are not the result of a conscious train of reasoning. Ingenuity consists of aiding the intuition through suitable arrangements of ideas and prior knowledge. For digital firms, advanced skills include abstract thinking such as writing complex code to build a platform and later integrate it with other applications; engaging in continuous and complex interaction with engineers, service development specialists, or branding teams; integrating insights from predictive analytics; negotiating contracts for vendors to join the platform; forecasting revenue growth with new digital technologies; etc. Nelson and Winter (1982) highlight three characteristics of these skills. First, they are programmatic, as they consist of a series of steps executed sequentially. Second, their underlying knowledge is tacit, even to the performer. Third, they involve multiple stages of choices, mostly made subconsciously. In essence, advanced skills are often impervious to digitalization, and can only be transferred, be it within or across countries, through highly socialized communities.

Generic skills perform routine, rule-based tasks such as, e.g., monitor and report on standard IT updates; conduct system quality checks following predetermined protocols; process customer complaints based on pre-established company policy; respond to general user questions; etc. These generic skills are either ubiquitous or can be generated in any location with some investment. 
They do not require the physical transfer of human capital.

Does digitalization enable the cross-border transfer of human capital FSAs? The answer varies for advanced versus generic skills. As discussed, advanced skills are difficult to embody in technology and hence digitalization does not add much to their tradability; i.e., the ability to use them temporarily in conjunction with resources not under the control of the firm in order to earn a higher return than their present best use within the firm (Chi, 1994). For example, McKinsey will still primarily work through the hierarchy mode to bring its expertise to a foreign market but will use digital technologies to facilitate international intrafirm transfer of advanced skills to that subsidiary. The digital connectivity afforded by the platform reduces the associated training, socialization, and monitoring costs and enables the advanced human capital FSA to be more mobile within the firm and across borders. This is the quintessential Kogut and Zander MNC, which leverages digitalization to internationalize more efficiently. If the advanced human capital FSA is coupled with a core technology FSA, the MNC will be able to compete effectively across the globe. Thus, digitalization increases the degree of firm-specificity of advanced skills and the ability to internally train and build the human capital with digital technologies.

Conversely, generic skills involve simple, rulebased, and repetitive tasks that can be codified and copied easily across borders (Kogut \& Zander, 1992). These skills are not specific to the firm or the location. Mostly, they are widely available or can be created in a new location with minimal selection and training. Digitalization commoditizes such generic skills even more. The question of transferability of generic skills to foreign markets is perhaps not so relevant: either they can be acquired locally, or local partners can deliver the service there. The more generic the skill is (e.g., shopping for a client from a preordered grocery list on the platform), the more substitutable it is in foreign markets with local talent, which can be bundled with the digital platforms. Uber's drive-assist technology is an apt illustration, as it enables even novice drivers who are unfamiliar with local geography, pricing, or customer support to become operator-partners with very minimal training. Hence, digitalization reduces the firm-specificity of generic skills and enables easier bundling of locally available human capital.
Overall, digitalization shrinks the transaction costs to bundle human capital skills across geographic boundaries, increasing these skills' scalability. Uber, e.g., can quickly scale operations worldwide as its digital platform enables foreign drivers to deliver services in their local markets. In the process, digitalization renders generic skills less firm-specific as they become easier to codify through the platform. Conversely, digitalization makes advanced skills harder to codify and, hence, more firm-specific. In sum:

Proposition 3: Digitalization increases a firm's ability to bundle its advanced and generic human capital FSAs with those in host markets through the digital platform. While digitalization increases the firm specificity of advanced human capital skills, it reduces the firm specificity of generic human capital skills.

A brief comment on AI's role is in order. Humans' ability to make a moral judgment, use system thinking across multiple and abstract concepts, apply empathy, etc. are uniquely human advanced skills that experts deem are difficult (still) for AI to learn. While technology may be evolving, companies would still depend on the employees who are capable of working with such highly specialized technologies. Thus, the firm-specific co-specialization of advanced human skills with AI would make it more difficult for rivals to identify which causal element yields the digital SMNC's success (Chi, 1994).

\section{Digitalization and Governance Choice Predictions} Based on the above propositions, we lastly suggest that digitalization extends the choice of the governance structure of market versus hierarchy by adding the digital network as a third choice, depending on whether the digital SMNCs deploy technology or human capital FSAs abroad. Buckley and Strange (2011: 461) note that internalization theory is concerned with the "precise configuration of the internal architecture of the firm; that is, its governance structure" (Buckley \& Strange, 2011: 462). The choice of governance structure - i.e., the institutional context within which transactions occur (Williamson, 1979) - pertains to the external (market) and internal (hierarchy) organization of the firm (Buckley \& Strange, 2011). This multichoice governance structure aligns with research noting that firms use a combination of foreign entry modes (Benito, Petersen, \& Welch, 2019; Hashai, Asmussen, Benito, \& Petersen, 2010). For 
digital SMNCs, the governance structure involves the creation of rules that determine how open the platform should be to external parties (Parker \& Van Alstyne, 2005). As such, digital networks are a hybrid governance choice: the platform creates a market mechanism of matching supply with demand, which is then internally managed by the SMNC with various degrees of centralization. Digital SMNCs can have a more or less centralized locus of control over the network, depending on how open the platform is and how important the FSA is for the digital SMNC's competitive advantage (Eisenmann, Parker, \& Van Alstyne, 2009, 2011).

We bring this insight explicitly into our analysis by discussing the emergence of the network as an ownership advantage $\left(\mathrm{O}_{\mathrm{n}}\right)$ that is distinct from traditional $\mathrm{O}_{a}$ and $\mathrm{O}_{t}$ advantages. For example, Uber's $\mathrm{O}_{a}$ technology advantage is its user-friendly platform comprising the digital interface and software algorithms for geolocation, driver guidance, workload allocation, payment calculation, reputation score-keeping, etc. Uber's $\mathrm{O}_{\mathrm{t}}$ transaction-based ownership advantage pertains to the ability of the system to learn and become more sophisticated in its execution through machine learning, which reduces transaction costs in the transportation market through accumulated experience with the digital network. Uber also enjoys network $\mathrm{O}_{n}$ advantages. The increasing returns or the network effects make the user base, typically the number of subscribers in the network, a major determinant of the cost structure of the service, its ability to develop new ideas, and a potential barrier for new entrants. Thus, as firms shift away from products to platform ecosystems, digitalization enables firms to internationalize through digital networks with foreign partners (Evans \& Gawer, 2016; Pamnani, 2017).

Digital networks are different from traditional strategic alliances in several important ways. Network research in IB has focused predominantly on relationships in physical space that require face-toface, tangible interactions (Holm et al., 1996, 1999; Powell, 1990). Conversely, members of digital ecosystems benefit from an expanded set of relationships due to a larger set of partner complementarities based on different partner roles: hubs, suppliers, complementors, users, etc. As such, relationships in digital networks are "at the level of the roles or groups of actors as opposed to the dyad, which is a fundamental shift from the usual mode of analysis" (Jacobides et al., 2018: 2265). Furthermore, while traditional alliances focus on risk mitigation in the dyadic relationship, digital networks aim to maximize the value for the ecosystem (Jacobides et al., 2018; Strange \& Humphrey, 2019). For users to benefit from network effects, they must affiliate (subscribe) with a digital network, whereas users do not have to do that when purchasing products or services from traditional alliances in physical space (Jacobides et al., 2018).

\section{Technology FSAs and governance choice}

Traditional internalization theory predicts that the hierarchy would be the most efficient governance choice to protect core technology FSAs (Buckley \& Casson, 1976; Narula, 2001). Peripheral technology FSAs can be outsourced as the firm's competitive advantage does not depend on them (Narula, 2001; Teece, 1986). We extend this traditional argument in two ways.

First, we propose that for digital SMNCs, the digital network is more efficient than the hierarchy (e.g., operating as a traditional hotel chain or a traditional taxi company) when deploying technology FSAs because the digital network becomes a network advantage $\left(\mathrm{O}_{\mathrm{n}}\right)$ for the firm (Sun \& Tse, 2009; Teece, 2018). With increasing digitalization, network size and quality emerge as an important resource for digital SMNCs (Eisenmann et al., 2011; Katz \& Shapiro, 1986; Martens, 2016). Economies of scope in data analytics enable digital SMNCs to collect larger and more diverse datasets that yield sharper business insights for the company than could smaller, non-integrated datasets (Martens, 2016). The digital platform also enables value maximization for the entire network, reducing the transaction costs needed to achieve the same value alone through the hierarchy, further enhancing the MNC's $\mathrm{O}_{\mathrm{t}}$ advantage (Collinson \& Narula, 2014). For example, Netflix entered India by partnering with local telecoms to integrate its core technology app with their payment and set-up boxes, so that customers can connect to and pay for Netflix access through their established phone and TV box contracts (Mitter, 2017). It costs less for Netflix to deploy its core technology on a digital network with local vendors who bear most of Netflix's entry setup costs than to build this technology in-house alone. It is also more efficient for Netflix to integrate the peripheral technology - payment system - of its network partners into its app than to develop it in-house. Peripheral technology FSAs like vendor payment systems are neither fully market-acquired nor fully firm-owned; rather, they are governed by the quasi-internalization mode of 
digital networks, whereby the partners on the network cooperate to co-specialize them. Bundling FSAs with local partners' know-how yields a sustainable advantage abroad (Chi, 1994; Collinson \& Narula, 2014). This is especially the case for digital SMNCs whose platforms have flexible user interface designs. The rise of new digital technologies improves the functionality of and the user's overall experience with the software deployed on the platform. This, in turn, facilitates user network effects, as users with more positive experiences with the platform interface design are less likely to switch to alternative platforms. Thus, in addition to $\mathrm{O}_{\mathrm{a}}$ and $\mathrm{O}_{\mathrm{t}}$, digitalization adds the $\mathrm{O}_{\mathrm{n}}$ as a network advantage for digital SMNCs.

Second, research on digital SMNCs has suggested that the level of openness of the digital network is critical for these firms' competitive advantage (Parker \& Van Alstyne, 2018). The locus of control over the digital network varies depending on whether the technology FSAs are core or peripheral. On one hand, the digital SMNC would centralize control over its network by limiting access of external developers to its core technology FSAs (e.g., applications or content). Such a network operates as a closed sponsorship and leads to greater value appropriation by the digital SMNC (Eisenmann et al., 2009). On the other hand, the digital SMNC decentralizes control over its network by providing greater access to third-party developers. This typically occurs for firms' peripheral technology FSAs, whereby the developers share responsibility for serving users with other network partners and help orchestrate the value creation on the platform. More decentralized networks lead to greater value adoption by external users (Eisenmann et al., 2009). Uber's core technology integrating geo-location services with ride-sharing - is patent-protected and not fully open to thirdparty developers (Levine, 2014). However, Uber opens its peripheral technologies to external developers so other companies can deliver their products to their clients quickly by integrating their technology with the Uber app. These arguments lead to the following proposition:

Proposition 4a: Digitalization enhances a firm's ability to exploit its core (peripheral) technology FSAs in foreign markets with a more (less) centrally controlled digital network.

\section{Human capital FSAs and governance choice}

Internalization theory posits that proprietary FSAs like advanced human capital skills are too complex and tacit, and hence, difficult to transfer to third parties internationally (Kogut \& Zander, 1992, 1993; Rugman \& Verbeke, 2003, 2004). Thus, they are unlikely to be acquired through external market transactions (Lepak \& Snell, 1999) and are best developed in-house (Buckley \& Casson, 1976; Rugman, 1981). Conversely, generic skills can be outsourced as the firm's competitive advantage does not depend on them (Narula, 2001; Teece, 1986).

We posit that this traditional logic would still hold for digital SMNCs' advanced human capital FSAs, but that digitalization requires more nuanced arguments. As tacit knowledge requires more faceto-face interactions (Narula, 2001), the hierarchy would continue to be most efficient for digital SMNCs to deploy their advanced human capital skills internationally. New digital technologies have increased the need for human capital with more advanced skills who know how to operate with, maintain, and extract the most value from these technologies. Due to the strong isolating mechanisms of co-specialized knowledge between humans and AI, advanced skills bundled with AI continue to be sticky and highly firm-specific under rising digitalization. However, because digitalization increases the intensity of advanced human capital skills, it would be more efficient for digital SMNCs to "acqui-hire" advanced human capital skills externally, subsequently integrating them into the hierarchy, than to develop them fully inhouse from scratch (Coyle \& Polsky, 2013: 281).

Acqui-hiring is the novel practice of acquiring only the highly specialized foreign team of individuals from a competitor by hiring the team within the digital SMNC, without acquiring the competitor's other products, services, or liabilities (Coyle \& Polsky, 2013; Paul, 2018). On one hand, acquihiring eliminates the time and investments needed to develop the team's talent anew in-house, which would be less efficient. On the other hand, acquihiring also eliminates the inefficiency of overpaying for acquiring the entire foreign company when the specific talent team is the only value-added of interest to the digital SMNC (Coyle \& Polsky, 2013). Acqui-hiring also allows the digital SMNC to benefit from the targeted team's portfolio of skills, removing the need for the digital SMNC to identify the specific causal mechanism and individual that yields the foreign team's success. Acqui-hired teams 
are then fully integrated into the hierarchy of the purchasing organization to reduce the risk of knowledge leakage (Chi, 1994). As such, acquihiring allows digital SMNCs to expand their foreign footprint by efficiently cherry-picking advanced human capital in host countries. For instance, Dubai-based Careem ride-sharing app - Uber's main rival in the Middle East - e.g., acqui-hired India's Commut bus shuttle team for their technology talent, aiming next to integrate and expand this talent to 14 countries (Paul, 2018).

In summary, generic skills are a commodity and do not justify the digital SMNCs to incur the costs (e.g., employee benefits, training, etc.) of managing and controlling them internally (Lepak \& Snell, 1999; Teece, 1986). Employees with generic skills are also highly mobile, which further exacerbates the risk of losing them if investing in their in-house development (Chi, 1994). Because generic human capital skills are easily substitutable with local partners' generic skills in foreign markets, companies avoid incurring such sunk costs (Becker, 1964; Lepak \& Snell, 1999). Accordingly, an MNC would not find it efficient to enter the foreign market only with generic skills as they can be easily substituted with a local partner's generic skills (e.g., Uber does not need to transfer its drivers to foreign markets as local drivers can sign up on the platform). Thus, contracting generic human capital skills from the foreign market, instead of transferring employees with generic skills abroad, is the most efficient solution for such an MNC. Taken together, these arguments lead to our final proposition:

Proposition 4b: Digitalization enhances a firm's ability to exploit advanced (generic) human capital FSAs in foreign markets at lower costs by internalizing (externalizing) them.

\section{DISCUSSION}

We provided an in-depth analysis of how digitalization affects internalization theory's assumptions about the nature of FSAs and predictions about their cross-country governance for digital SMNCs. Internalization theory has often been faulted for not being a dynamic one and overly focused on hierarchies (Buckley, 2016; Dunning, 1981). Buckley (2016: 80) envisions that "[p]roblems with internalization theory need to be problems with the frontiers of social science...Identifying lags behind this feasible frontier is the first task of IB research, pushing beyond it is the major goal." Our paper serves as a useful stepping stone toward this goal, strengthening internalization theory for the digital economy.

We started this paper with the question: How does digitalization alter internalization theory's assumptions about the nature of FSAs and predictions about their governance in cross-border transactions? Our framework provides a simple way to reorient the analysis of FSAs. By decomposing FSAs into technology and human capital, and subsequently into core versus peripheral technology and advanced versus generic human capital, we proposed how modularity, skill complexity, and bundling can be integrated within internalization theory in the digital age. The governance choice predictions in Figure 1 summarize how the technology and human capital FSAs lead to different governance modes, with the network mode becoming more common. Depending on the criticality of the core or peripheral technology, the network becomes more or less centrally controlled. Similarly, depending on the composition of human capital - advanced or generic - there is increased internalization or externalization of skills, respectively. Thus, our paper extends others in this special issue that also elaborate on conditions under which MNCs would externalize their activities across the value chain (Benito et al., 2019; Strange \& Humphrey, 2019).

Our analysis raises three important observations for internalization theory in the digital economy. First, digitalization challenges the definition of the MNC, which has traditionally invoked the investment of physical assets abroad as a critical indicator of multinationality. Instead, new digital technologies enable MNCs to exchange information and enter foreign markets through digital networks. Thus, in the digital age, MNCs can be born digitally by simply granting consumers worldwide access to their products and services through online apps and expand digitally by entering host countries with digital network ecosystems. The concept of place shifts from physical, territorial attributes to digital, information flow-based characteristics (Kobrin, 2017). The firm is also no longer just a standalone entity (Dunning \& Wymbs, 2001). Should IB research then rebrand the MNC as "the DNE" - i.e., digitally networked ecosystem - shifting the unit of analysis from the firm to the overall ecosystem?

Second, digitalization also challenges a key underlying role behind the market: price-setting. Prior to digitalization, consumer preferences 
tended to be over-simplified and condensed down to price due to the information processing constraints of the analog economy (Schonberger \& Ramge, 2018). Digitalization alters the concept of the market from a common physical space for buyer-seller interactions incentivized by the pricing mechanism to a data-rich environment that buyers and suppliers co-create through new digital technologies (Sambamurthy et al., 2003; Schonberger \& Ramge, 2018). Data-rich platforms provide firms with the ability to characterize their consumers not just based on price preferences but also based on personal taste, convenience, etc. (Thornhill, 2018). As the marginal cost of copying and transferring data-rich digital goods globally is almost zero, their pricing is driven less by marginal cost and more by value-optimization for the users on the network (Schonberger \& Ramge, 2018; Thornhill, 2018).

Third, while we are still in the early stages of markets transforming into data-rich environments, the social implications from digitalization are already being debated (New York Times, 2014). With rising digitalization, it is not just a question of how digitalization alters the governance of technology and human capital FSAs. Digitalization takes this analysis a step further, showing that digital SMNCs can use their technology FSAs to substitute for their human capital FSAs, which can in turn widen income inequality and unemployment.

\section{Future Research Venues}

While our discussion focused on the benefits from digitalization, future research can complement ours and study the dark side of digitalization (New York Times, 2014). In addition to its numerous benefits, digitalization also threatens job stability in traditional sectors such as transportation, retail, finance, etc. (Hook, 2017). Brick-and-mortar retail outlets are increasingly closing shop as consumer demand moves online. What should the role of the state be in securing the socio-economic welfare of its citizens in the digital economy, especially in emerging markets? A greater access of society to IT advances can spur economic growth by lifting rural communities out of poverty (Kenny, 2017). Such IT and education skill set advances can also help curtail backlash against globalization (Kobrin, 2017). Government-industry cyber security partnerships that aim to strengthen encryption and increase awareness of MNCs' staff about cyber security threats and various mitigation mechanisms have also been long advocated (Dunning \& Wymbs, 2001).

Our study opens the possibility to bring SMNCs to the forefront of IB research. Services contribute increasingly to employment and economic development in many countries (Kundu \& Lahiri, 2015). Yet, SMNCs face substantive challenges in internationalization as they attempt to provide intangible, perishable, and experience-based services globally for profit (Pamnani, 2017). SMNCs' internationalization has remained under-explored (Kundu \& Lahiri, 2015), and digitalization provides new ways to reconceptualize both theory and practice in this arena. Although we considered manufacturing firms beyond the scope of this paper, our framework is easily extendable and generalizable, as more and more manufacturing firms draw more of their revenue comes from services, and their value chains are also being transformed by digital technologies such as AI, big data, and 3D printing. We highlighted the role of human capital in how SMNCs transfer knowledge internationally and protect it from possible misappropriation. MNCs can be powerful agents of social change by "bundling" technology with local human capital, an idea that digitalization makes possible.

The literature has so far perceived network as a governance mode independently from network as a resource. The simultaneity of the two functions introduces several complexities that need to be resolved. We have introduced the idea of the network advantage, $\mathrm{O}_{\mathrm{n}}$, to explicitly consider the economics of networks, which opens fruitful venues for future research. Is the $\mathrm{O}_{n}$ advantage location-bound or semi-permeable to other countries? The IB literature is rich with examples of semi-permeable advantages - e.g., brands, distribution and marketing advantages - and provides useful priors to build on. The pervasiveness of the network architecture in an MNC paves ways for better knowledge governance in an $\mathrm{MNC}$, bringing the study of "orchestration" roles feasible and useful (Dhanaraj \& Parkhe, 2006; Pitelis \& Teece, 2018).

\section{CONCLUSION}

Digital networks would likely become the dominant organizational mode and a key feature of IB. As the MNC becomes a spatially distributed entity, co-creating value with global partners, data and information become even more central. Digitalization not only brings down information costs 
through communication technologies but also heralds a more efficient way of coordinating within the network, depending on the type of FSA technology or human capital - that the firm leverages for its internationalization. Our study paves the way to analyze how MNCs become digitally networked orchestrators not only of their subsidiaries across countries but also of their global ecosystem partners, specializing in connecting buyers with sellers instantaneously through digital platforms. IB as a field should be prepared to see more of asset-light internationalization enabled by digitalization, ushering in co-owned and co-managed global networks. Indeed, the "globally integrated enterprise" that Sam Palmisano, exChairman of IBM, envisioned in the 2000s is perhaps finally here, made possible by digitalization.

\section{ACKNOWLEDGEMENTS}

We are grateful to the special issue editors - Christian Asmussen, Tailan Chi, Sumit Kundu, and Rajneesh Narula - and to the four anonymous reviewers for their insightful guidance and suggestions through the multiple revisions of this paper. A previous version of the paper received the FIU/AIB Best Theory Paper award at the AIB 2018 conference held at Minneapolis. We are also grateful for helpful feedback on earlier versions of this manuscript from the participants at the special issue workshop held at the AIB in June 2018,

\section{REFERENCES}

Asmussen, C. G., Larsen, M., \& Pedersen, T. 2016. Organizational adaptation in offshoring: The relative performance of home- and host-based learning strategies. Organization Science, 27(4): 911-928.

Becker, G. 1964. Human Capital (2nd edn). New York: Columbia University Press.

Benito, G., Petersen, B., \& Welch, L. 2019. The global value chain and internalization theory: A commentary. Journal of International Business Studies. https://doi.org/10.1057/ s41267-019-00218-8.

Bharadwaj, A., El Sawy, O., Pavlou, P., \& Venkatraman, N. 2013. Digital business strategy: Toward a next generation of insights. MIS Quarterly, 37(2): 471-482.

Brouthers, K., Geisser, K., \& Rothlauf, F. 2016. Explaining the internationalization of ibusiness firms. Journal of International Business Studies, 47(5): 513-534.

Buckley, P. J. 2016. The contribution of internalization theory to international business: New realities and unanswered questions. Journal of World Business, 51: 74-82.

Buckley, P. J., \& Casson, M. C. 1976. The future of the multinational enterprise. London: Macmillan.

Buckley, P. J., \& Strange, R. 2011. The governance of the multinational enterprise: Insights from internalization theory. Journal of Management Studies, 48(2): 460-470. and additional colleagues including Afonso Fleury, Sali Li, Arvind Parkhe, and Vivek Tandon.

\section{NOTES}

${ }^{1}$ The IB literature has used the terms, tradability, mobility, and transferability in an interchangeable manner. Tradability is used in the context of exchange of strategic assets between firms, an example of which is licensing a technology to a foreign manufacturer (Chi, 1994). Mobility is used in the context of movement of factor resources from one firm to another, an example of which is the movement of a senior executive or a product division to another firm (Tseng, Tansuhaj, Hallagan, \& McCullough, 2007). Mobility implies absence of firm specificity, which is a requirement for tradability. Transferability is used in the context of movement of knowledge assets, either within a firm, as in knowledge transfer from headquarters to subsidiary, or through markets, as in licensing.

${ }^{2}$ Digital SMNCs still own some physical assets as part of their growth strategies: e.g., Amazon bought Whole Foods stores, Uber purchased self-driving cars, Google's Waymo bought minivans to equip them with driverless technology, etc. Nonetheless, digital SMNCs are more knowledge-heavy and still physical asset-light in comparison to traditional, asset-heavy brick-and-mortar retailers, wholesalers, and manufacturers.

Chen, L., Shaheer, N., Yi, J., \& Li, S. 2018. The international penetration of ibusiness firms: Network effects, liabilities of outsidership and country clout. Journal of International Business Studies. https://doi.org/10.1057/s41267-018-0176-2.

Chi, T. 1994. Trading in strategic resources: Necessary conditions, transaction cost problems, and choice of exchange structure. Strategic Management Journal, 15(4): 271-290.

Coase, R. 1937. The nature of the firm. Economica, 4(4): 386-405.

Coff, R., \& Kryscynsky, D. 2011. Drilling for micro-foundations of human capital-based competitive advantages. Journal of Management, 37(5): 1429-1443.

Collinson, S., \& Narula, R. 2014. Asset recombination in international partnerships as a source of improved innovation capabilities in China. The Multinational Business Review, 22(4): 394-417.

Coyle, J., \& Polsky, G. 2013. Acqui-hiring. Duke Law Journal, 63(2): 281-346.

Deagon, B. 2017. Amazon Echo keeps big lead over Google Home in digital assistants. Investors' Business Daily, https:// www.investors.com/news/technology/amazon-echomaintains-big-lead-over-google-home-in-digital-assistants/. Accessed December 22, 2018. 
Dhanaraj, C., \& Parkhe, A. 2006. Orchestrating innovation networks. Academy of Management Review, 31(3): 659-669.

Dunning, J. H. 1981. Explaining international direct investment position of countries: Towards a dynamic or developmental approach. Weltwirtschaftliches Archiv, 117(1): 30-64.

Dunning, J. H. 1988. The eclectic paradigm of international production: A restatement and some possible extensions. Journal of International Business Studies, 19(1): 1-31.

Dunning, J. H., \& Wymbs, C. 2001. The challenge of electronic markets for international business theory. International Journal of the Economics of Business, 8(2): 273-301.

Eden, L. 2016. Strengthening the global trade and investment system for sustainable development, ICTSD/World Economic Forum.

Eisenmann, T., Parker, G., \& Van Alstyne, M. 2009. Opening platforms: How, when and why? In A. Gawer (Ed.), Platforms, Markets and innovation. Northampton, MA: Edward Elgar Publishing.

Eisenmann, T., Parker, G., \& Van Alstyne, M. 2011. Platform envelopment. Strategic Management Journal, 32(12): 1270-1285.

Evans, P. C. \& Gawer, A. 2016. The rise of the platform enterprise: a global survey. In The emerging platform economy series, No. 1., The Center for Global Enterprise. https://www. thecge.net/app/uploads/2016/01/PDF-WEB-Platform-Survey 01_12.pdf.

Gaur, A., Pattnaik, C, Lee, J. Y., \& Singh., D. 2019. Internalization advantage and subsidiary performance: The role of business group affiliation and host country characteristics. Journal of International Business Studies, 50: 1-30.

Gawer, A. 2009. Platforms, markets, and innovation. Cheltenham: Edward Elgar.

Gopal, R., Ramesh, R., \& Whinston, A. 2002. Microproducts in a digital economy: Trading small, gaining large. International Journal of Electronic Commerce, 8(2): 9-30.

Harzing, A. W., Pudelko, M., \& Sebastian Reiche, B. 2016. The bridging role of expatriates and inpatriates in knowledge transfer in multinational corporations. Human Resource Management, 55(4): 679-695.

Hashai, N., Asmussen, C. G., Benito, G. R. G., \& Petersen, T. 2010. Technological knowledge intensity and entry mode diversity. Management International Review, 50: 659-681.

Hennart, J.-F. 1993. Explaining the 'swollen middle': Why most transactions are a mix of market and hierarchy. Organization Science, 4(4): 529-547.

Hennart, J.-F. 2009. Down with MNE-centric theories! Market entry and expansion as the bundling of MNE and local assets. Journal of International Business Studies, 40(9): 1432-1454.

Holm, D., Eriksson, K., \& Johanson, J. 1996. Creating value through mutual commitment to business network relationships. Strategic Management Journal, 20(5): 467-486.

Holm, D., Eriksson, K., \& Johanson, J. 1999. Value creation through mutual commitment to business network relationships. Strategic Management Journal, 20: 467-486.

Hook, L. 2017. Out of road: driverless vehicles and the end of the trucker, Financial Times, https://www.ft.com/content/ 2d70469c-140a-11e7-b0c1-37e417ee6c76.

Accessed November 24, 2017.

Jacobides, M., Cennamo, C., \& Gawer, A. 2018. Towards a theory of ecosystems. Strategic Management Journal, 39: 2255-2276.

Katz, M., \& Shapiro, C. 1986. Technological adoption in the presence of network externalities. Journal of Political Economy, 94(4): 822-841.

Kenny, D. 2017. Bill Gates is wrong: the solution to Al taking jobs is training, not taxes, Wired, https://www.wired.com/ 2017/04/bill-gates-wrong-solution-ai-taking-jobs-trainingnot-taxes/. Accessed November 24, 2017.

Kobrin, S. 2017. Bricks and mortar in a borderless world: Globalization, the backlash, and the multinational enterprise. Global Strategy Journal, 7: 159-171.
Kogut, B., \& Zander, U. 1992. Knowledge of the firm, combinative capabilities, and the replication of technology. Organization Science, 3(3): 383-397.

Kogut, B., \& Zander, U. 1993. Knowledge of the firm and the evolutionary theory of the multinational corporation. Journal of International Business Studies, 24(4): 625-645.

Kogut, B., \& Zander, U. 2003. A memoir and reflection: Knowledge and an evolutionary theory of the multinational firm 10 years later. Journal of International Business Studies, 34: 505-515.

Kotha, S., Rindova, V., \& Rothaermel, F. 2001. Assets and actions: Firm-specific factors in the internationalization of U.S. internet firms. Journal of International Business Studies, 32(4): 769-791.

Kundu, S., \& Lahiri, S. 2015. Turning the spotlight on service multinationals: New theoretical insights and empirical evidence. Journal of International Management, 21: 215-219.

Langlois, R. 2002. Modularity in technology and organization. Journal of Economic Behavior \& Organization, 49(1): 19-37.

Lepak, D., \& Snell, S. 1999. The human resource architecture: Toward a theory of human capital allocation and development. Academy of Management Review, 24(1): 31-48.

Levine, B. 2014. Uber opens up its API - and creates a new platform, Venture Beat, https://venturebeat.com/2014/08/20/ uber-opens-up-its-api-and-creates-a-new-platform/, Accessed October 6, 2018

Lippman, S., \& Rumelt, R. P. 1982. Uncertain imitability: An analysis of interfirm differences in efficiency under competition. Bell lournal of Economics, 13: 418-438.

Lundan, S. 2009. What are ownership advantages? Multinational Business Review, 18(1): 51-69.

Mahoney, J., \& Kor, Y. 2015. Advancing the human capital perspective on value creation by joining capabilities and governance approaches. Academy of Management Perspectives, 29(3): 296-308.

Marriott. 2019. Marriott International: News Center. http:// news.marriott.com/2017/03/marriott-international-mapsfuture-growth-investor-day/ Accessed February 19, 2019.

Martens, B. 2016. An economic policy perspective on online platforms, IRC Technical Reports, https://ec.europa.eu/jrc/ sites/jrcsh/files/JRC101501.pdf. Accessed October 6, 2018.

Mathur, N. 2018. Regional languages give Indian startups a voice of their own, LiveMint, https://www.livemint.com/ Companies/b6veJ1Hm10o3tiNT7cp3sl/Regional-languagesgive-Indian-startups-a-voice-of-their-own.html, Accessed December 9, 2018.

Mauro, T. 2015. Adopting microservices at Netflix: lessons for architectural design, DZone, https://dzone.com/articles/ adopting-microservices-netflix. Accessed October 6, 2018

Mitter, S. 2017. Netflix is serious about India. Here is proof. Mashable, https://mashable.com/2017/03/06/netflix-dealtelecom-dth-operators-india/\#CqoPjug_NOqH. Accessed May 5, 2018.

Modgil, S. 2017. Can Amazon tap the next billion with the India launch of Echo and Alexa this Diwali?, Inc42, https://inc42. com/features/amazon-india-echo-alexa/. Accessed December 9, 2018.

Narula, R. 2001. Choosing between modes of non-internal technological activities by firms: Some technological and economic factors. Technology Analysis \& Strategic Management, 13: 152-170.

Nelson, R., \& Winter, S. 1982. An evolutionary theory of economic change. Cambridge: The Belknap Press of Harvard University Press.

New York Times. 2014. The dark side of the sharing economy, New York Times, https://www.nytimes.com/2014/05/01/ opinion/the-dark-side-of-the-sharing-economy.html. . Accessed November 24, 2017.

Pamnani, H. 2017. 'Become digital' if not 'born digital', Entrepreneur, https://www.entrepreneur.com/article/298535. Accessed October 9, 2018. 
Parker, G., \& Van Alstyne, M. 2005. Two-sided network effects: A theory of information product design. Management Science, 51: 1494-1504.

Parker, G., \& Van Alstyne, M. 2018. Innovation, openness, and platform control. Management Science, 64(7): 3015-3032.

Paul, B. 2018. Careem acquihires bus aggregator Commut; Shuttle to take over local opps, Nwes Corp VC Circle, https:// www.vccircle.com/careem-acqui-hires-bus-aggregatorcommut-shuttl-to-take-over-local-ops/. Accessed October 15, 2018.

Pham, S. 2018. Uber's big Chinese rival Didi is pumping money into Brazil, CNN, https://money.cnn.com/2018/01/04/ technology/didi-99-acquisition-uber-brazil/index.html. Accessed February 9, 2019.

Pitelis, C., \& Teece, D. 2018. The New MNE: 'Orchestration' theory as envelop for internalization theory. Management International Review, 58(4): 523-539.

Polanyi, M. 1967. The tacit dimension. London: Routledge \& Kegan Paul Ltd.

Powell, W. 1990. Neither market nor hierarchy: Network forms of organization. Research In Organizational Behavior, 12: 295-336.

Rasmussen, J. 1983. Skills, rules, and knowledge; signals, signs, and symbols, and other distinctions in human performance models. IEEE Transactions on Systems, Man, and Cybernetics, 3: 257-266.

Reed, R., \& Defillippi, R. 1990. Causal ambiguity, barriers to imitation, and sustainable competitive advantage. Academy of Management Review, 15(1): 88-102.

Roehl, T. W., \& Truitt, J. 1987. Stormy open marriages are better: Evidence from US, Japanese and French cooperative ventures in commercial aircraft. Columbia Journal of World Business, 22(2): 87-95.

Rugman, A. M. 1981. Inside the multinationals: The economics of internal markets. New York: Columbia University Press.

Rugman, A. M., \& Verbeke, A. 2003. Extending the theory of the multinational enterprise: Internalization and strategic management perspectives. Journal of International Business Studies, 34: 125-237.

Rugman, A. M., \& Verbeke, A. 2004. A perspective on regional and global strategies of multinational enterprises. Journal of International Business Studies, 35(1): 3-18.

Sambamurthy, V., Bharadwaj, A., \& Grover, V. 2003. Shaping agility through digital options: Reconceptualizing the role of information technology in contemporary firms. MIS Quarterly, 27(2): 237-263.

Schonberger, V., \& Ramge, T. 2018. Reinventing capitalism in the age of big data. New York: Basic Books.

Simon, H. A. 1962. The architecture of complexity. Proceedings of the American Philosophical Society, 106(6): 467-482.

Simon, H. A. 1985. What we know about the creative process. In R. L. Kuhn (Ed.), Frontiers in creative and innovative management pp. 3-20. Cambridge: Ballinger.

Singh, N., \& Kundu, S. 2002. Explaining the growth of e-commerce corporations (ECCs): An extension and application of the eclectic paradigm. Journal of International Business Studies, 33(4): 679-697.

Solomon, B. 2016. How Airbnb expanded to 190 countries by thinking 'Glocal', Forbes, https://www.forbes.com/sites/ briansolomon/2016/05/03/how-airbnb-expanded-to-190countries-by-thinking-glocal/\#4320cbf97e91. Accessed February 19, 2019.

Sondergaard, P. 2015. The internet of things will give rise to the algorithm economy, Thomson Reuters, https://blogs. thomsonreuters.com/answerson/algorithm-economyinternet-of-things/, Accessed November 27, 2018.

Strange, R., \& Humphrey, J. 2019. What lies between market and hierarchy? Insights from internalization theory and global value chain theory? Journal of International Business Studies. https://doi.org/10.1057/s41267-018-0186-0.
Strange, R., \& Zucchella, A. 2017. Industry 4.0, global value chains and international business. Multinational Business Review, 25(3): 174-184.

Suarez, F. 2005. Network effects revisited: The role of strong ties in technology selection. Academy of Management Journal, 48(4): 710-720.

Suarez, F., \& Kirtley, J. 2012. Dethroning an established platform. MIT Sloan Management Review, 53(4): 35-41.

Sun, M., \& Tse, E. 2009. The resource-based view of competitive advantage in two-sided markets. Journal of Management Studies, 46(1): 45-64.

Teece, D. J. 1986. Profiting from technological innovation. Research Policy, 15(6): 285-306.

Teece, D. J. 2018. Business models and dynamic capabilities. Long Range Planning, 51: 40-49.

Thornhill, J. 2018. The rise of the information economy threatens traditional companies, Financial Times, https:// www.ft.com/content/6c6c730e-3298-11e8-ac4810c6fdc22f03, Accessed July 21, 2018.

Tseng, C. H., Tansuhaj, P., Hallagan, W., \& McCullough, J. 2007. Effects of firm resources on growth in multinationality. Journal of International Business Studies, 38(6): 961-974.

Turing, A. M. 1939. Systems of logic based on ordinals. Proceedings of the London Mathematical Society, 2(1): 161-228.

Tutle, B. 2018. Netflix just got hammered by Wall Street for its growth rates. Here is how many subscribers it has now, Time, http://time.com/money/5341022/netflix-subscribers-2018stock-amazon-prime/. Accessed December 9, 2018.

Wang, S., \& Li, D. 2019. Responding to public disclosure of corporate social irresponsibility in host countries: Information control and ownership control. Journal of International Business Studies.. https://doi.org/10.1057/s41267-019-00224-w.

Williamson, O. E. 1979. Transaction-cost economics: The governance of contractual relations. Journal of Law and Economics, 22: 233-261.

Yu, H. 2018. What Netflix has that Google and Netflix don't. Forbes, https://www.forbes.com/sites/unicefusa/2018/11/20/ a-day-to-celebrate-defend-and-promote-child-rights/ \#426019232e4d. Accessed November 27, 2018.

\section{ABOUT THE AUTHORS}

Elitsa R Banalieva is an Associate Professor of International Business at Northeastern University. Her research studies the geographic scope and institutional contexts that enable or constrain the strategies of family and non-family firms from emerging markets. She received her Ph.D. in Business Economics and Public Policy from Indiana University, Bloomington.

Charles Dhanaraj is the H.F. "Gerry" Lenfest Professor of Strategy at Fox School of Business, Temple University, the Founding Executive Director of Fox's Center for Translational Research in Business, and a Fellow of the Academy of International Business (AIB). His research focuses on strategic partnerships, global innovation, and emerging markets. He received his Ph.D. from Ivey Business School, Western University in Canada. 
Open Access This article is distributed under the terms of the Creative Commons Attribution 4.0 International License (http://creativecommons. org/licenses/by/4.0/), which permits unrestricted use, distribution, and reproduction in any medium, provided you give appropriate credit to the original author(s) and the source, provide a link to the Creative Commons license, and indicate if changes were made.

Publisher's Note Springer Nature remains neutral with regard to jurisdictional claims in published maps and institutional affiliations.

Accepted by Christian Geisler Asmussen, Tailan Chi, and Rajneesh Narula, Special Issue Guest Editors, 2 April 2019. This article has been with the authors for five revisions. 